\title{
3-Chloro-2,5-dihydroxybenzyl alcohol activates human cervical carcinoma HeLa cell apoptosis by inducing DNA damage
}

\author{
YANJUN ZHANG ${ }^{1}$, EUN-YOUNG AHN ${ }^{1}$, YAHONG JIANG ${ }^{4}$, DONG-KYOO KIM ${ }^{1,2}$, SUNG-GOO KANG ${ }^{3}$, \\ CHUNFU WU ${ }^{4}$, SHIN-WON KANG ${ }^{5,6}$, JANG-SU PARK ${ }^{5}$, BYENG WHA SON ${ }^{7}$ and JEE H. JUNG ${ }^{8}$
}

\begin{abstract}
${ }^{1}$ Biohealth Product Research Center, ${ }^{2}$ Department of Biomedicinal Chemistry, and Institute of Functional Materials, ${ }^{3}$ Department of Biology, Inje University, Kimhae 621-749, South Korea; ${ }^{4}$ School of Pharmaceutical, Shenyang Pharmaceutical University, Shenyang 110016, P.R. China; ${ }^{5}$ Department of Chemistry and Centre for Innovative Bio-physio sensor Technology, Pusan National University, Busan 609-735; ${ }^{6}$ Korea Basic Science Institute, Daejeon 305-333; ${ }^{7}$ Department of Chemistry, Pukyong National University, Busan 608-737; ${ }^{8}$ College of Pharmacy, Pusan National University, Busan 609-735, South Korea
\end{abstract}

Received April 2, 2007; Accepted July 2, 2007

\begin{abstract}
We have isolated 3-chloro-2,5-dihydroxybenzyl alcohol (CHBA) from marine-derived fungus Aspergillus sp. and characterized its apoptosis-inducing properties against human cervical carcinoma (HeLa) cells. Significantly decreased rates of proliferation and viability $\left(\mathrm{IC}_{50} \sim 35 \mu \mathrm{M}\right)$ as well as evidence of apoptosis were observed with CHBA. Nuclear changes observed under fluorescence microscopy confirmed apoptosis occurrence and showed a typical pattern of chromatin condensation. Furthermore, results from Annexin V-FITC/PI dual staining indicated that CHBA induced earlier apoptosis of HeLa cells in a concentrationand time-dependent manner. CHBA also induced cytochrome $c$ release from mitochondria into the cytosol and subsequent caspase activation involving caspase-9 and -3 by Western blotting assay was observed. We also found that CHBA was able to induce DNA damage and inhibit DNA replication followed by $S$ phase arrest. The very sensitive alkaline microgel electrophoresis technique (comet assay) was used for estimation of the CHBA-induced DNA single strand breaks. These findings suggest that CHBA induces HeLa cell apoptosis by cytochrome $c$ release and caspase activation pathway and that the effect of CHBA on apoptosis of HeLa cells is associated with DNA damage. Because of the ease of synthesis and structural manipulation, CHBA may have the potential to be developed into an anticancer agent.
\end{abstract}

Correspondence to: Dr Dong-Kyoo Kim, Department of Biomedicinal Chemistry, Institute of Functional Materials and Biohealth Product Research Center, Inje University, Kimhae 621-749, South Korea

E-mail: chemkdg@inje.ac.kr

Key words: 3-chloro-2,5-dihydroxybenzyl alcohol, apoptosis, DNA damage, caspase, mitochondria

\section{Introduction}

Marine-derived fungi have proven to be rich sources of structurally novel and biologically active secondary metabolites, which are emerging as a significant new chemical resource for drug discovery $(1,2)$. The compound 3-chloro2,5-dihydroxybenzyl alcohol (CHBA) (Fig. 1) was first isolated from a terrestrial fungus Phoma sp. in 1971 by Sequin-Frey and Tamm and then from two additional terrestrial fungi: Penicillium canadense (3) and Phyllosticta sp. (4). In the present study, CHBA was isolated for the first time from the genus Aspergillus sp. In previous studies, CHBA was associated with biological functions including phytotoxic browning effect on red clove leaves (4) and antifouling and antimicrobial activities (5). However, the biological properties of CHBA with regard to antiproliferative effects and to molecular mechanisms of the therapeutic effects have not been examined.

In this study, we examined the action of CHBA on human cervical carcinoma HeLa cells. Many reports have demonstrated that exposure of cancer cells to chemotherapeutic drug can lead to DNA damage $(6,7)$. The most abundant lesion produced is the DNA single strand breakage, which can be sensitively detected by the alkaline microgel electrophoresis (comet) assay $(8,9)$. The comet assay has also been previously used to detect DNA strand breaks in antitumor studies $(10,11)$. Cells can respond to DNA damage either by undergoing cell cycle arrest, by facilitating DNA repair, or by undergoing apoptosis.

Apoptosis, a fundamental cellular activity that maintains the physiological balance of the organism, is involved in immune defense machinery (12). It plays a protective role against carcinogenesis by eliminating either damaged cells or those excess abnormal cells that proliferated due to induction by various chemical agents $(12,13)$. Morphologically, apoptosis is characterized by shrinkage of the cell, dramatic reorganization of the nucleus, active membrane blebbing and, ultimately, fragmentation of the cell into membrane-enclosed vesicles (apoptotic bodies) (14). Recent experiments have demonstrated that mitochondria play an 


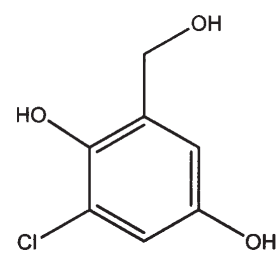

Figure 1. The structure of 3-chloro-2,5-dihydroxybenzyl alcohol (CHBA).

essential role in apoptotic commitment (15). Upon apoptotic stimulation, several important events occur at the mitochondria, including the release of cytochrome $c$. Once cytochrome $c$ is released from the mitochondria into cytosol, the cell is committed to die by either apoptosis or necrosis. This cytosolic cytochrome $c$ interacts with apoptotic protease activation factor 1 (Apaf-1), which induces its association with procaspase-9, thereby triggering processing and consequent activation of caspase- 9 . The activated caspase- 9 in turn cleaves downstream effect caspases (such as caspase-3), initiating apoptotic execution (16).

Activation of the cellular apoptotic axis is a current strategy for the treatment of human cancer. Emerging evidence has demonstrated that the anticancer activities of certain chemotherapeutic agents involve the induction of apoptosis, which is regarded as the preferred way to manage cancer (17). It is therefore, essential to identify novel apoptosis-inducing compounds that are candidate antitumor agents. Small molecules, like CHBA, have great potential as anticancer drugs because they can be easily synthesized and structurally manipulated for selective development. Clarification of the mode of action of CHBA may be important in developing its applications.

\section{Materials and methods}

Chemicals. PI/RNase staining buffer for cell cycle analysis and Annexin-FITC kit for apoptosis were from BD Biosciences Pharmingen, USA DMSO and PBS ( $\mathrm{pH}$ 7.4) were purchased from Sigma Chemical Co. Eagle's minimum essential medium (EMEM), fetal bovine serum (FBS), penicillin-streptomycin and trypsin-EDTA were obtained from Hyclone Laboratories (Logan, UT). CCK-8 was purchased from Dojin Laboratories (Osaka, Japan). All other chemicals were of analytical reagent grade.

Preparation of $C H B A$. CHBA was isolated from the marinederived fungus Aspergillus sp. and was a gift from Dr B.H. Son's lab of Pukyong National University, Korea. Stock solutions of CHBA was prepared in dimethyl sulfoxide (DMSO) and kept at $-20^{\circ} \mathrm{C}$. Further dilutions were made immediately prior to each experiment.

Cell lines. HeLa cells obtained from American Type Culture Collection (ATCC) were cultured in EMEM medium supplemented with $10 \%$ fetal bovine serum at $37^{\circ} \mathrm{C}\left(5 \% \mathrm{CO}_{2}\right)$ in a humidified atmosphere.

Cell viability and proliferation assay. HeLa cells were plated at $5 \times 10^{3}$ cells into each well of a 96-well microplate. After the cells were incubated for $24 \mathrm{~h}, \mathrm{CHBA}$ at various concentrations was added to each well as treatment and an appropriate volume of drug vehicle (DMSO) was used as the control. The plate was incubated an additional $48 \mathrm{~h}$. CCK-8 reagent $(10 \mu \mathrm{l})$ was added and incubated for a further $2 \mathrm{~h}$. Cell viability was assessed by WST-8 [2-(2-methoxy4-nitrophenyl)-3-(4-nitrophenyl)-5-(2,4-disulfophenyl)-2Htetrazolium], an indicator that is reduced by dehydrogenases in cells to give a yellow-colored product (formazan), which is soluble in cell culture medium. Optical density for living cells was read at $450 \mathrm{~nm}$ in a multi-microplate reader (synergy HT, BIO-TEK ${ }^{\circledR)}(18)$.

For the cell proliferation assay, cells seeded at $5 \times 10^{3}$ per ml medium in 96-well plates were treated without or with CHBA $(17.5,35$, and $70 \mu \mathrm{M})$ for various times. The viable cells were determined by Cell Counting Kit-8. Each experiment was repeated at least 3 times.

Measurement of apoptotic morphology. HeLa cells were distributed $\left(1 \times 10^{5}\right.$ cells/well) into a 24 -well plate and allowed to adhere overnight. The cells were treated with CHBA $(35 \mu \mathrm{M})$ respectively for $12 \mathrm{~h}$. Non-treated wells received an equivalent volume of DMSO $(<0.1 \%)$. Optic phase-contrast photographs were taken with a Nikon ${ }^{\mathrm{TM}}$ Phase Contrast-2, ELWD 0.3 inverted microscope. For the Hoechst 33342 nuclear staining assay (19), HeLa cells were seeded into a 24-well plate containing 10 -mm-diameter sterile glass coverslips. After CHBA treatment, each well was washed with PBS and fixed with $200 \mu 1$ of fixing solution (methanol: acetic acid $=3: 1$ ) for $15 \mathrm{~min}$ at $4^{\circ} \mathrm{C}$. The cells were rinsed twice with PBS and stained for $10 \mathrm{~min}$ in $500 \mu \mathrm{l}$ of Hoechst $33342(5 \mu \mathrm{g} / \mathrm{ml})$ in the dark. After rinsing with sterile double-distilled water twice, the coverslips were taken out and mounted on the slides. Observations were made under ultraviolet light using a DAPI filter. Each experiment was repeated at least 3 times.

Annexin V-FITC/PI apoptosis analysis. The cells $\left(5 \times 10^{5}\right.$ cells in $60 \mathrm{~mm}^{2}$ dish) treated with or without CHBA were collected by trypsinization and washed with precooled PBS via centrifugation. The pellet was then resuspended in $100 \mu 1$ of binding buffer and stained with $5 \mu \mathrm{l}$ of Annexin V-FITC (BD PharMingen) and $10 \mu \mathrm{l}$ of PI $(50 \mu \mathrm{g} / \mathrm{ml})$ for $15 \mathrm{~min}$ at room temperature $\left(15-25^{\circ} \mathrm{C}\right)$ in the dark. The samples were then read in a FACS calibur flow cytometer. In each analysis, 10,000 events were recorded. Analyses were performed by the CellQuest software (Becton-Dickinson Instruments, Franklin Lakes, NJ).

Western blot assay. The cells (1x $10^{6}$ cells in $100 \mathrm{~mm}^{2}$ dish) treated with or without CHBA were harvested and washed with cold PBS. Cell pellets were lysed in protein extraction solution (PRO-PREP) for $20 \mathrm{~min}$ on ice. Lysates were centrifuged at $13,000 \mathrm{rpm}$ for $5 \mathrm{~min}$ at $4{ }^{\circ} \mathrm{C}$. Protein contents in the supernatant were measured using the Bradford protein assay (Bio-Rad, Hercules, CA). Total cellular protein $(50 \mu \mathrm{g})$ was separated on 5-16\% SDS-PAGE and electro-phoretically transferred onto PVDF membranes (Amersham Biosciences, Buckinghamshire, UK). The membranes were blocked with $3 \%$ non-fat milk (Sigma) in Tris-buffered saline containing $0.1 \%$ Tween-20 and then incubated with primary polyclonal 
antibodies (BD PharMingen), including cyto-chrome $c$, caspase-9, caspase-3, and actin. The primary anti-body complex was then stained with horseradish peroxidaseconjugated secondary antibodies. Protein bands were detected using an enhanced chemiluminescence detection system according to the manufacturer's manual (Amersham Pharmacia Biotech, Amersham, UK). To re-probe the membrane with another primary antibody, antibodies were stripped with Blot Restore Membrane Rejuvenation Kit (Chemicon, CHBA).

DNA content analysis. The cells $\left(5 \times 10^{5}\right.$ cells in $60 \mathrm{~mm}^{2}$ dish) treated with or without CHBA were collected by trypsinization and washed with precooled PBS via centrifugation. The cells were suspended in PBS, fixed with $70 \%$ ethanol (v/v). Samples were washed with PBS and stained with PI/RNase staining buffer (BD PharMingen) for $15 \mathrm{~min}$ at $4^{\circ} \mathrm{C}$. The number of cells in different phases of the cell cycle was analyzed using a FACScan flow cytometer analysis system (Becton-Dickinson, San Jose, CA), and 20,000 events were analyzed for each sample. The percentage of cells in the different phases of cell cycle was determined using Modfit software (Becton-Dickinson Instruments). All experiments were performed in duplicate and yielded similar results.

$\left[{ }^{3} \mathrm{H}\right]$ thymidine incorporation assay. The $\left[{ }^{3} \mathrm{H}\right] \mathrm{dTTP}$ incorporation was performed as previously described (20). Briefly, HeLa cells were applied to 12 -well plates in growth medium (EMEM $+10 \%$ FBS). After the cells had grown to $70-80 \%$ confluence, they were rendered quiescent by incubation for $24 \mathrm{~h}$ in EMEM containing 2\% FBS. EMEM supplemented with $10 \%$ FBS and 35 or $50 \mu \mathrm{M}$ of CHBA (or control) was added to cells and the cultures were allowed to incubate for 21 and $45 \mathrm{~h}$. $\left[{ }^{3} \mathrm{H}\right] \mathrm{dTTP}$ was added at $1 \mu \mathrm{Ci} / \mathrm{ml}$ and incubated further for $3 \mathrm{~h}$. Incorporated $\left[{ }^{3} \mathrm{H}\right] \mathrm{dTTP}$ was extracted in cell lysis buffer and measured in a liquid scintillation counter.

Single cell gel electrophoresis. To examine the DNA damage in these single-cell suspensions, we performed an alkaline single-cell gel electrophoresis (comet assay). The comet assay was carried out based on the method of Singh with some modifications (21). Briefly, the cells (treated without or with CHBA for 6,12 , and $24 \mathrm{~h}$ ) were pelleted and resuspended in $0.5 \%$ low melting point agarose at $37^{\circ} \mathrm{C}$ and layered on a frosted microscope slide previously coated with a thin layer of $1 \%$ normal melting agarose and kept for $10 \mathrm{~min}$ on ice. After solidification, the slides were immersed in lysing solution $(2.5 \mathrm{M} \mathrm{NaCl}, 100 \mathrm{mM}$ EDTA, $10 \mathrm{mM}$ Tris, $\mathrm{pH} 10,1 \%$ Triton $\mathrm{X}-100$ and $10 \%$ DMSO for $1 \mathrm{~h}$ and $30 \mathrm{~min}$ at $4^{\circ} \mathrm{C}$ ). The slides were then incubated in an alkaline buffer (0.3 M NaOH, $1 \mathrm{mM} \mathrm{Na} \mathrm{N}_{2}$-EDTA) for $40 \mathrm{~min}$ at $4^{\circ} \mathrm{C}$. The electrophoresis was carried out for $40 \mathrm{~min}$ at $25 \mathrm{~V}$. After electrophoresis, the slides were washed with $0.4 \mathrm{M}$ Tris $(\mathrm{pH}$ $7.5)$ and stained with ethidium bromide $(1 \mu \mathrm{g} / \mathrm{ml})$ and observed under a fluorescence microscopy (Leica DM LB2).

Statistical analysis. Each experiment was repeated for at least 3 times and results were expressed as mean \pm SEM in some quantitative experiments. All the results reported were obtained from at least 3 independent experiments with similar results.

\section{Results}

CHBA induced the inhibition of HeLa cell growth and apoptotic cell death. To explore the cytotoxicity of CHBA, we determined $\mathrm{IC}_{50}$ values in HeLa cells using the watersoluble tetrazolium salt WST-8 as an indicator of cell viability (18). Treatment of HeLa cells with various concentrations of CHBA for $48 \mathrm{~h}$ caused a dose-dependent decrease in cell number, with an $\mathrm{IC}_{50} \sim 35 \mu \mathrm{M}$ (Fig. 2). Cell proliferation assays were used to investigate the inhibition of growth caused by CHBA. Low concentration of CHBA (up to $17.5 \mu \mathrm{M}$ ) resulted in growth inhibition in HeLa cells, but not in cell death, with approximately $30 \%$ growth inhibition being detected after 48-h treatment (Fig. 2B). However, fullblown cytotoxicity required CHBA concentrations $>35 \mu \mathrm{M}$. Investigations of cells treated with high concentrations of CHBA by light and fluorescence microscopy revealed the morphological features of apoptosis. Treatment with $35 \mu \mathrm{M}$ of CHBA for $12 \mathrm{~h}$ significantly induced apoptotic cell death as indicated by condensed and fragmented nuclei (Fig. 2C).

To obtain further evidence for the induction of apoptosis by CHBA in HeLa cells, Annexin V and PI double staining assay was performed. Significant differences were observed between the vehicle and CHBA-treated cells. Under control conditions, $\sim 89 \%$ of HeLa cells treated with vehicle alone were viable [Fig. 2D(a), Annexin V-PI-], while $~ 8 \%$ were early apoptotic cells [Fig. 2D(a), Annexin V+PI-]. After 12-h treatment with 35 and $50 \mu \mathrm{M}$ CHBA, only 8.13 and $19.69 \%$ were apoptotic, respectively, but after $48 \mathrm{~h}$, the proportion of apoptotic cells increased to 14.40 and $31.91 \%$ respectively. In addition, the percentage of late apoptotic cells (or necrosis cells) stained both by Annexin V-FITC and PI (Annexin $\mathrm{V}+\mathrm{PI}+$ ) showed no differences. Therefore, in comparison with control cells, CHBA-treated HeLa cells displayed an increase in apoptosis in a concentration- and time-dependent manner.

CHBA-induced apoptosis is caspase-dependent and associated with cytochrome $c$ release. Caspases comprise a family of cysteine proteases with a central role in the executional phase of apoptosis (22). Initiator caspases (including -8, $-9,-10$ and -12 ) are closely coupled to proapoptotic signals. Once activated, these caspases cleave and activate downstream effector caspases (including -3, -6 and -7), which in turn cleave cytoskeletal and nuclear proteins, and finally induce apoptosis. We first evaluated whether caspasedependent signal pathways were involved in the apoptotic cell death induced by CHBA in HeLa cells. We measured activation of capase -3 and -9 by Western blot assay. Treatment of HeLa cells with 35 and $50 \mu \mathrm{M}$ of CHBA for 24 and $48 \mathrm{~h}$ resulted in dramatic increases in caspase- 3 protein and decreases in procaspase-9 protein level (Fig. 3). To address the question of whether CHBA was able to induce cytochrome $c$ release from mitochondria, a cytoplasm fraction prepared from HeLa cells was incubated in the presence (35 and $50 \mu \mathrm{M}$ ) or absence of CHBA for 24 and 


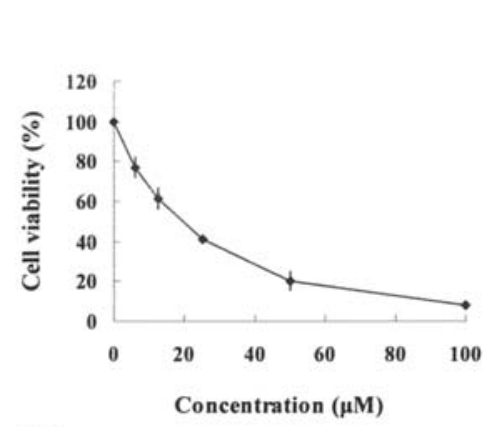

(A)

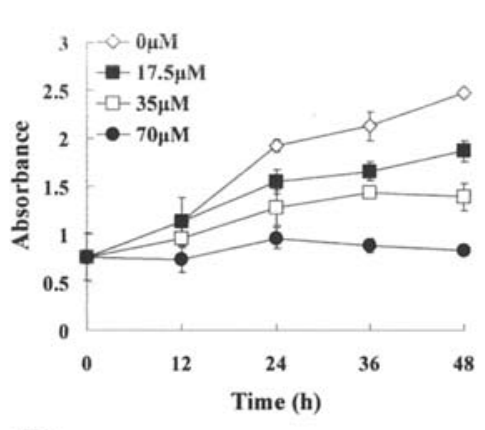

(B)

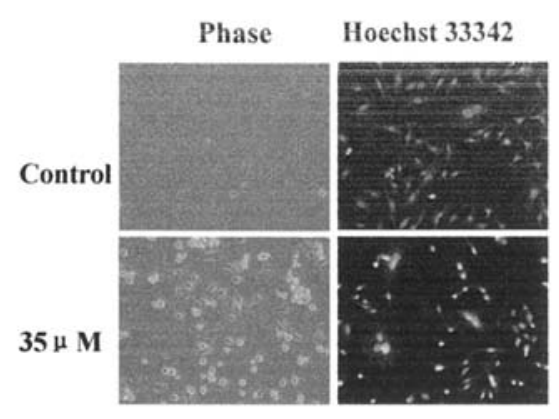

(C)

(b)

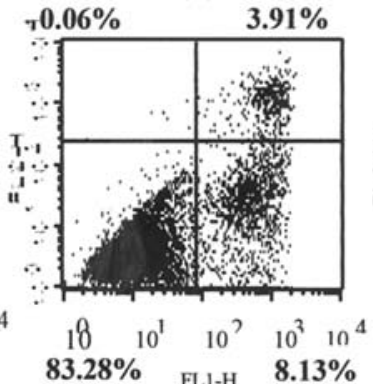

(e)

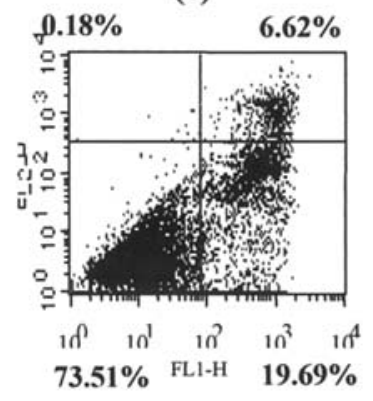

(c)

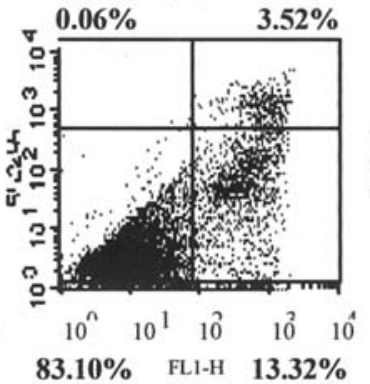

(f)

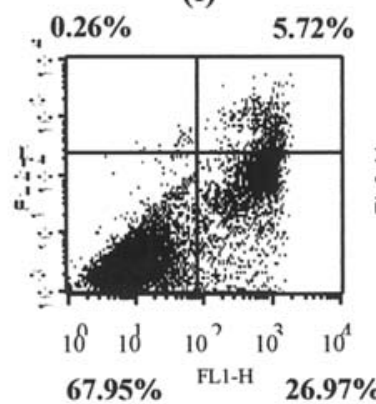

(d)

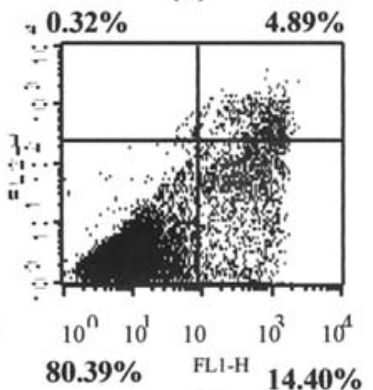

(g)

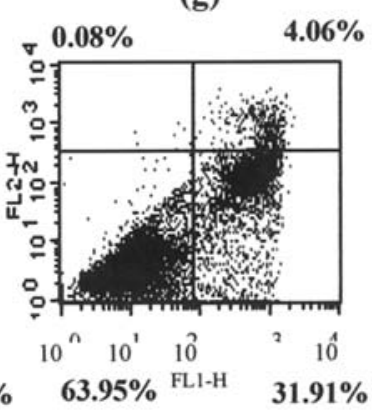

Figure 2. Induction of apoptosis by CHBA. HeLa cells were treated with various concentrations of CHBA for $48 \mathrm{~h}$ (A) or with $17.5,35$ and $70 \mu \mathrm{M}$ of CHBA for 12, 24, 36 and $48 \mathrm{~h}$ (B). Relative cell viability was determined by WST-8 and 1-methoxy PMS and is presented as the percentage of control cells. Data are shown as means \pm SD of 3 independent experiments. (C) HeLa cells were treated with $35 \mu \mathrm{M}$ of $\mathrm{CHBA}$ for $12 \mathrm{~h}$. Nuclei was characterized under light and fluorescence microscopy. After fixing, cells were stained with Hoechst 33342 and photographed with a fluorescence microscope using blue filter. Magnification x160. (D) Measurement of apoptosis population induced by CHBA. HeLa cells were treated with vehicle alone (a), $35 \mu \mathrm{M}$ of CHBA for $12 \mathrm{~h}$ (b), $24 \mathrm{~h}$ (c), $48 \mathrm{~h}$ (d), $50 \mu \mathrm{M}$ of CHBA for $12 \mathrm{~h}$ (e), $24 \mathrm{~h}$ (f), $48 \mathrm{~h}$ (g). Cells were harvested at the indicated time points, and stained with Annexin V-FITC/PI and analyzed for apoptosis by flow cytometry. The cell populations shown in the lower left represent living cells, lower right represents earlier apoptosis cells, upper right represents late apoptosis or necrosis cells and upper left represents pre-necrotic cells. All experiments were performed in duplicate and gave similar results.

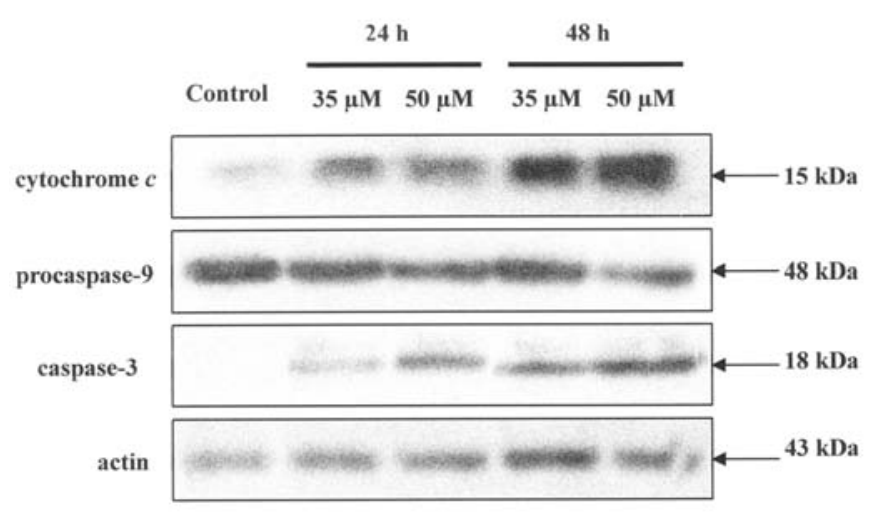

Figure 3. Involvement of protein activation in CHBA-induced apoptosis. HeLa cells were treated with 35 and $50 \mu \mathrm{M}$ of CHBA for indicated time periods. Extracts from untreated or CHBA-treated cells were assayed by Western blot analysis.
$48 \mathrm{~h}$. The cytoplasm fraction markedly increased the cytochrome $c$ protein level in a concentration-dependent manner (Fig. 3), suggesting that the CHBA-induced apoptosis of HeLa cells was via caspase-dependent mitochondrial pathway.

CHBA-induced apoptosis is associated with an increased $S$ phase population. The cell growth and inhibition are both tightly mediated through cell cycle control (23), and dysregulation of cell cycle progression has been implicated in the initiation of apoptosis (24-26). To determine whether CHBA-induced apoptosis is associated with cell cycle-specific changes, we measured the cell cycle distribution of HeLa cells that had been treated with 35 and $50 \mu \mathrm{M}$ of CHBA for 24 and $48 \mathrm{~h}$. After 48-h treatment, the percentage of cells in $\mathrm{S}$ phase significantly increased from a control value of $29.38 \%$ to $35.29 \%$ and $37.01 \%$ in cells treated with CHBA (35 and $50 \mu \mathrm{M}$, respectively) (Fig. 4D-F). This increase in $\mathrm{S}$ 
$\mathbf{0} \mu \mathrm{M}$ A)

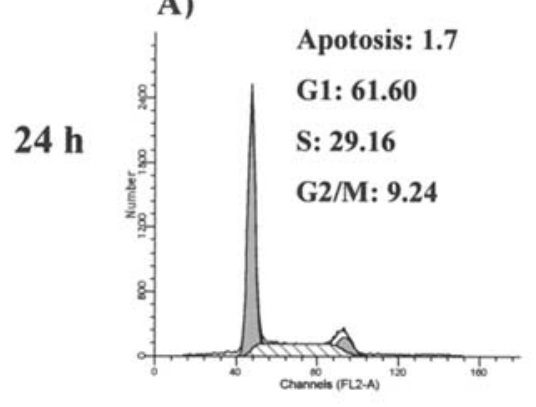

B)

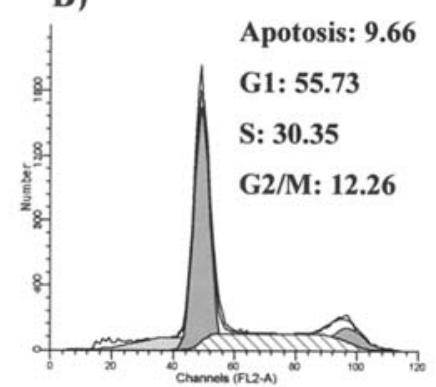

E)

D)
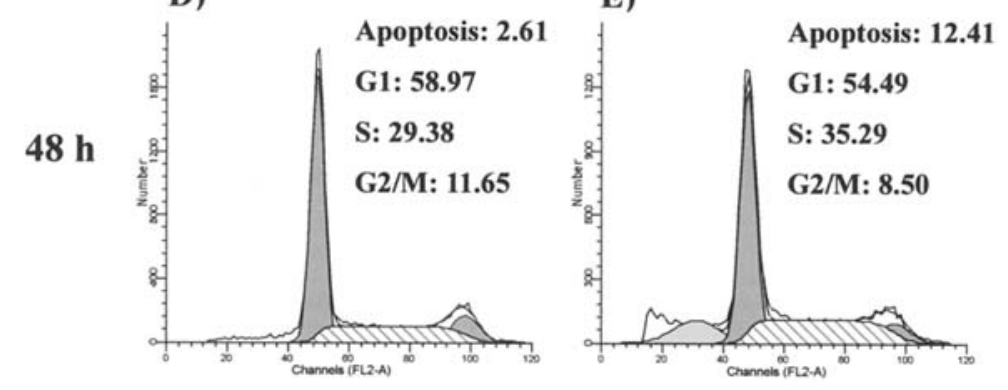

$35 \mu \mathrm{M}$

$50 \mu \mathrm{M}$

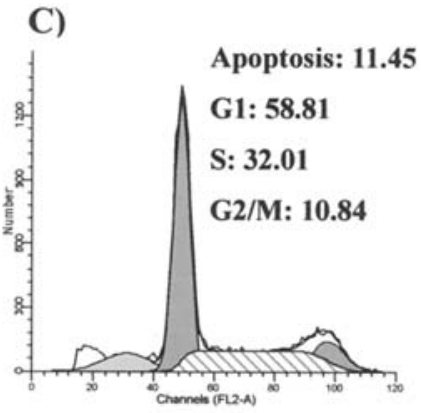

F)

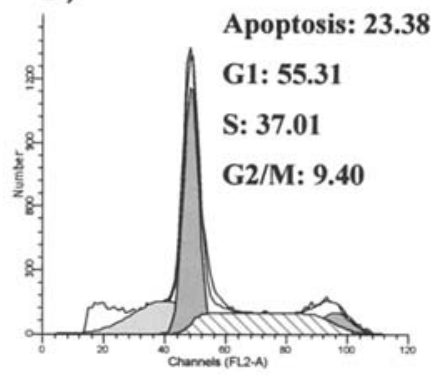

Figure 4. Effect of CHBA on cell cycle progression of HeLa cells. HeLa cells were treated with vehicle alone or with 35 or $50 \mu \mathrm{M}$ of CHBA for 24 h (A-C), and $48 \mathrm{~h}(\mathrm{D}-\mathrm{F})$. DNA content was analyzed by flow cytometry with PI staining. The cell cycle distribution was calculated as the percentage of cells containing apoptosis, G0/G1, S and G2/M phase. Data are representative of three independent experiments.

phase cells occurred at the expense of decreasing the $\mathrm{G} 2 / \mathrm{M}$ cell population, while the population of the cells in G0/G1 phase was not affected. We also observed the appearance of a peak corresponding to a population of cells with apoptotic DNA content that changed in a time- and concentrationdependent manner.

CHBA inhibits DNA replication, associated with induction of DNA damage. Since our data demonstrated that HeLa cells treated with CHBA accumulated in $\mathrm{S}$ phase, we questioned whether the increased $S$ phase population is due to inhibition of DNA replication. After treatment with 35 or $50 \mu \mathrm{M}$ CHBA, the incorporation of $\left[{ }^{3} \mathrm{H}\right]$ thymidine decreased by $\sim 40$ and $70 \%$, respectively, with exposure times of 12 and $24 \mathrm{~h}$ having essentially the same effect (Fig. 5A). We further hypothesized that CHBA could induce DNA damage that would lead to the inhibition of DNA replication, which would then be responsible for blockage of $\mathrm{S}$ phase progression. To test this hypothesis, we implemented an alkaline singlecell gel electrophoresis comet assay, a sensitive method by which DNA single strand breaks at the single-cell level can be monitored. When cells were treated with $35 \mu \mathrm{M}$ of CHBA for $6 \mathrm{~h}$, DNA damage started to be evident, as indicated by the increased tail of DNA migration (Fig. 5B). After $12 \mathrm{~h}$ of treatment with CHBA, almost the entire population of HeLa cells contained damaged DNA. Under the same conditions, the S population had slightly increased (Fig. 4), and apoptosis had just started to be detectable (Fig. 2D). Thus, CHBA induces DNA strand breaks before $\mathrm{S}$ phase accumulation and apoptosis induction.

\section{Discussion}

Successful treatment with chemotherapeutic agents is largely dependent on the ability of the drugs to trigger cell death in tumor cells. Therefore, novel inducers of apoptosis provide a new therapeutic approach for anti-cancer drug design. Previous studies demonstrated that certain phytochemicals present in medicinal herbs exert anti-tumorigenic activity by inducing apoptosis in cancer cells. Toward the goal of developing novel chemotherapeutic agents, this report describes the selective in vitro killing of human cervical carcinoma HeLa cells by CHBA. We found that CHBA inhibits the growth of human cervical carcinoma HeLa cells, with the morphological changes of CHBA-treated HeLa cells showing typical apoptotic phenomena, such as nuclear condensation and DNA fragmentation. And we also found that CHBA-induced apoptosis was caspase-dependent, associating with cytochrome $c$ release. In addition, CHBAinduced apoptosis was preceded by induction of DNA damage, and inhibition of $\mathrm{S}$ phase progression. The order of the potency of CHBA to induce DNA damage matched well with its potency to inhibit $S$ phase progression and to induce apoptosis.

Mitochondria play essential roles in apoptosis through the redistribution of intermembranous mitochondrial proteins, such as cytochrome $c$. The significance of cytochrome $c$ to the apoptotic process was revealed by the finding that mitochondrial released cytochrome $c$ combines with Apaf-1, procaspase-9 and dATP in the cytosol, producing active caspase-9 $(15,16)$. The activation of this initiator caspase then leads to the proteolytic activation of caspase-3, the 
(A)

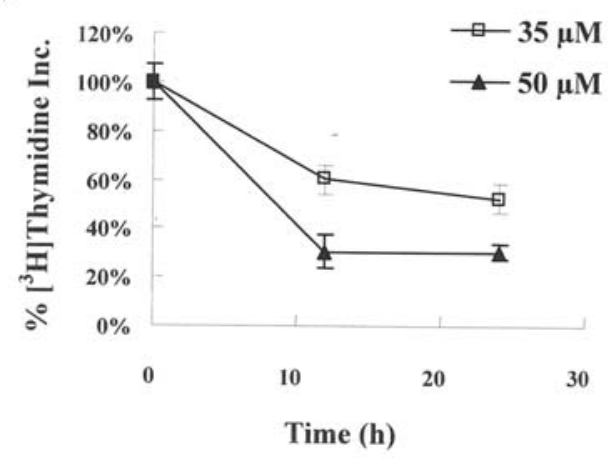

(B)

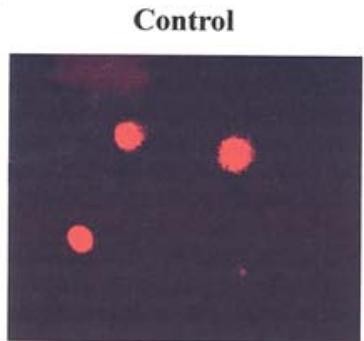

$12 \mathrm{~h}$
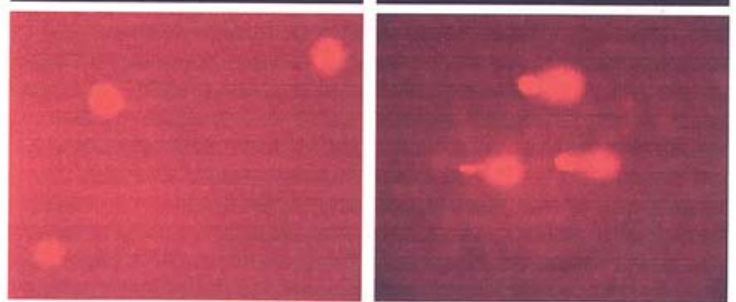

Figure 5. CHBA inhibits DNA replication and induces DNA strand breaks in HeLa cells. (A) $\left[{ }^{3} \mathrm{H}\right]$ thymidine incorporation assay. HeLa cells were either untreated (as a control, indicated by $0 \mathrm{~h}$ ), or pretreated with 35 and $50 \mu \mathrm{M}$ of CHBA for the indicated hours. After that, $\left[{ }^{3} \mathrm{H}\right]$ thymidine was added, followed by an additional 3-h incubation. The amount of $\left[{ }^{3} \mathrm{H}\right]$ thymidine incorporated was then analyzed by scintillation counting. Standard deviations are shown with error bars from a mean of at least 3 different experiments. (B) CHBA-induced DNA single strand breaks in HeLa cells. Cells were incubated with or without $35 \mu \mathrm{M}$ of CHBA for indicated times. Single-cell gel electrophoresis was determined as described in Materials and methods. Results are representative of 3 independent experiments.

primary effector caspase of the cell. This pathway is referred to as the mitochondrial pathway of caspase activation. Consistent with this pathway, CHBA treatment was able to induce mitochondrial cytochrome $c$ release along with caspase-9 and -3 activations (Fig. 3).

Many traditional pharmacological agents induce cell death in a cell cycle-dependent manner (26-28). We have found that CHBA at $35 \mu \mathrm{M}$ induces an $\mathrm{S}$ phase arrest, associated with apoptosis induction (Fig. 4). During S phase of the cell division cycle, cells replicate their DNA. In this phase, chromosomal DNA is replicated precisely once as a prelude to its segregation to the daughter cells at mitosis. If DNA replication is blocked by inhibitor or the template is damaged by radiation or other factors, signals are generated that can induce cell-cycle arrest or apoptosis (29-31). Therefore, we hypothesized that CHBA-induced S phase arrest and apoptosis might relate with its effect on DNA replication. Our exciting finding that $\left[{ }^{3} \mathrm{H}\right]$ thymidine incorporation was inhibited by CHBA treatment $12 \mathrm{~h}$ after administration (Fig. 5A) supports this idea. Inhibition of DNA replication can be caused by multiple mechanisms, including DNA damage. Indeed, results from comet assay showed that nearly $100 \%$ of the cell population contained DNA stand breaks after only $6 \mathrm{~h}$ of incubation with CHBA (Fig. 5B). However, no increases of earlier apoptotic cells as compared to controls after 12 -h treatment were noted (Fig. 2D), suggesting that the apoptosis-associated DNA fragmentation had not yet occurred. While our data strongly suggest that CHBA has the ability to induce DNA strand breaks, the mechanism of breakage remains elusive. Upon repair of this damage, progression through the cell cycle resumes. The cell's alternative to repairing damaged cells is simply to eliminate them through the process of apoptosis. Thus, as a cell progresses through the cell cycle, it must determine whether to complete cell division, to arrest growth to repair cellular damage, or to undergo apoptosis if the damage is too severe. Therefore, we can conclude that CHBA induces DNA strand breaks at as early as $6 \mathrm{~h}$ and can also inhibit the incorporation of $\left[{ }^{3} \mathrm{H}\right]$ thymidine within $12 \mathrm{~h}$, before any cell cycle change has taken place. Our data indicate that CHBA induced cell cycle arrest in order to allow DNA repair. As expected, these mechanisms also result in $\mathrm{S}$ phase arrest and apoptosis.

In conclusion, our study provides experimental evidence that CHBA-induced HeLa cell apoptosis was accompanied with a significant DNA condensation and apoptotic body formation. CHBA induces apoptosis in HeLa cells by stimulating cytochrome $c$ release followed by activation of caspase- 9 and -3 . In this study, CHBA induced S-phase cell cycle arrest and inhibition of DNA replication. However, the severe DNA damage is beyond the capacity of the DNA repair system. In order to eliminate the damaged cells, the apoptosis was observed after treatment with CHBA in HeLa cells.

To date, few reports have included the isolation of components from marine-derived fungi which have apoptosis activity, and the present study serves as the first attempt to evaluate the action of 3-chloro-2,5-dihydroxybenzyl alcohol on HeLa cells. Although the effect of CHBA on upstream trigger factor(s) that induce mitochondrial cytochrome $c$ translocation and ultimately cause cell death should be further investigated, our current studies indicate that CHBA has great potential as a lead compound that could be developed into a novel anticancer drug.

\section{Acknowledgments}

This work was supported by grant No. (R01-2004-00010467-0) from the Basic Research Program of the Korea Science and Engineering Foundation.

\section{References}

1. Blunt JW, Copp BR, Munro MH, Northcote PT and Prinsep MR: Marine natural products. Nat Prod Rep 20: 1-48, 2003.

2. Faulkner D: Marine natural products. Nat Prod Rep 19: 1-48, 2002.

3. McCorkindale NJ, Roy TP and Hutchingson SA: Isolation and synthesis of 3-chlorogentisyl alcohol. Metabolite of Penicillium canadense. Tetrahedron 28: 1107-1111, 1972.

4. Sakamura S, Ito J and Sakai R: Phytotoxic metabolites of phyllosticta Sp. Agric Biol Chem 35: 105-110, 1971. 
5. Kwong T, Miao L, Li XC and Qian PY: Novel antifouling and antimicrobial compound from a marine-derived fungus Ampelomyces sp. Marine Biotechnol 8: 634-640, 2006.

6. Han Z, Wei W, Dunaway S, et al: Role of p21 in apoptosis and senescence of human colon cancer cells treated with camptothecin. J Biol Chem 277: 17154-17160, 2002.

7. Kowalska-Loth B, Girstun A, Piekielko A and Staron K: SF2/ ASF protein inhibits camptothecin-induced DNA cleavage by human topoisomerase I. Eur J Biochem 269: 3504-3510, 2002.

8. Lee AJ, Hodges NJ and Chipman JK: Modified comet assay as a biomarker of sodium dichromate-induced oxidative DNA damage: optimization and reproducibility. Biomarkers 9: 103-115, 2004.

9. Singh NP, Penn PE, Pendergrass WR and Wolf NS: White lightmediated DNA strand breaks in lens epithelial cells. Exp Eye Res 75: 555-560, 2002.

10. Cardile V, Scifo C, Russo A, et al: Involvement of HSP70 in resveratrol-induced apoptosis of human prostate cancer. Anticancer Res 23: 4921-4926, 2003.

11. Woods JA, Young AJ, Gilmore IT, Morris A and Bilton RF: Measurement of menadione-mediated DNA damage in human lymphocytes using the comet assay. Free Radic Res 26: 113-124, 1997.

12. Hengartner MO: The biochemistry of apoptosis. Nature 407: 770-776, 2000

13. Brown JM and Wounters BG: Apoptosis, p53, and tumor cell sensitivity to anticancer agents. Cancer Res 59: 1391-1399, 1999.

14. Earnshaw WC: Nuclear changes in apoptosis. Curr Opin Cell Biol 7: 337-343, 1995

15. Green DR and Reed JC: Mitochondria and apoptosis. Science 281: 1309-1312, 1998

16. Li P, Nijhawan D, Budihardjo I, Srinivasula SM, Ahmad M, Alnemri ES and Wang X: Cytochrome $c$ and Datp-dependent formation of Apaf-1/caspase-9 complex initiates an apoptotic protease cascade. Cell 91: 479-489, 1997.

17. Fisher DE: Apoptosis in cancer therapy: crossing the threshold. Cell 78: 539-542, 1994.

18. Tominaga $\mathrm{H}$, Ishiyama $\mathrm{M}$, Ohseto $\mathrm{F}$, Sasamoto $\mathrm{K}$, Hamamoto $\mathrm{T}$, Suzukj K and Watanabe M: A water-soluble tetrazolium sait useful for colorimetric cell viability assay. Anal Commun 36: 47-50, 1999.
19. Allen S, Sotos J, Sylte MJ and Czuprynski CJ: Use of Hoechst 33342 staining to detect apoptotic changes in bovine mononuclear phagocytes infected with Mycobacterium avium subsp. paratuberculosis. Clin Diagn Lab Immunol 8: 460-464, 2001 .

20. Lin SY, Liu JD, Chang HC, Yeh SD, Lin CH and Lee WS Magnolol suppresses proliferation of cultured human colon and liver cancer cells by inhibiting DNA synthesis and activating apoptosis. J Cell Biochem 84: 532-544, 2002.

21. Singh NP: Microgels for estimation of DNA strand breaks, DNA protein crosslinks and apoptosis. Mutat Res 455: 111-127, 2000.

22. Vaux DL and Korsmeyer SJ: Cell death in development. Cell 96: 245-254, 1999.

23. Sanchez I and Dynlacht BD: New insights into cyclins, CDK, and cell cycle control. Semin Cell Dev Biol 16: 311-321, 2005.

24. Lee S, Christakos S and Small MB: Apoptosis and signal transduction: clues to a molecular mechanism. Curr Opin Cell Biol 5: 286-291, 1993

25. Dou QP: Putative roles of retinoblastoma protein in apoptosis. Apoptosis 2: 5-8, 1997.

26. Smith DM, Gao G, Zhang X, Wang G and Dou QP: Regulation of tumor cell apoptotic sensitivity during the cell cycle (Review). Int J Mol Med 6: 503-507, 2000.

27. Meikrantz W, Gisselbrecht S, Tam SW and Schlegel R: Activation of cyclin A-dependent protein kinases during apoptosis. Proc Natl Acad Sci USA 91: 3754-3758, 1994.

28. Orren DK, Petersen LN and Bohr VA: Persistent DNA damage inhibits S-phase and G2 progression and results in apoptosis. Mol Biol Cell 8: 1129-1142, 1997.

29. Pizer ES, Chrest FJ, DiGiuseppe JA and Han WF: Pharmacological inhibitors of mammalian fatty acid synthase suppress DNA replication and induce apoptosis in tumor cell lines. Cancer Res 58: 4611-4615, 1998.

30. Jiang YH, Ahn EY, Ryu SH, Kim DK, Park JS and Kang SW: Mechanism of cell cycle arrest by (8E,13Z,20Z)-strobilinin/ (7E,13Z,20Z)-felixinin from a marine sponge Psammocinia sp Oncol Rep 14: 957-962, 2005.

31. Jiang YH, Ahn EY, Ryu SH, Kim DK, Park JS and Yoon HJ: Cytotoxicity of psammaplin A from a two-sponge association may correlate with the inhibition of DNA replication BMC Cancer 4: 70, 2004. 